\title{
New Building for Mining Department of the University of Leeds.
}

THE new mining building which was officially opened by Viscount Chelmsford on Sept. 30 marks the first stage in the reconstruction scheme rendered necessary by the growth of the University of Leeds. Its erection has been made possible by the generosity of the Yorkshire Coal Owners' Association, which contributed $£ 25,000$ to the general building fund of the University, and of the Miners' Welfare Committee, which gave $£ 10,000$.

The main building is of three stories, and while the accommodation it provides is considered adequate for the immediate future, there exists considerable scope for extension should the need arise. The front of the building consists of Portland stone, and has been built to conform with the general architectural plans for the new University building scheme. The roof of the building is flat and is intended for use in the testing of surveying instruments and for latitude and azimuth observations.

On the top floor is a large well-lighted drawing office, a spacious room meantime used as a museum, a students' common room and departmental library, a research laboratory, and a large lecture theatre. In the museum numerous mining exhibits, historical and modern, are to be found. The wide corridors in both the top and middle floors are also utilised for the convenient display of geological specimens from many parts of the Empire and other exhibits of con-

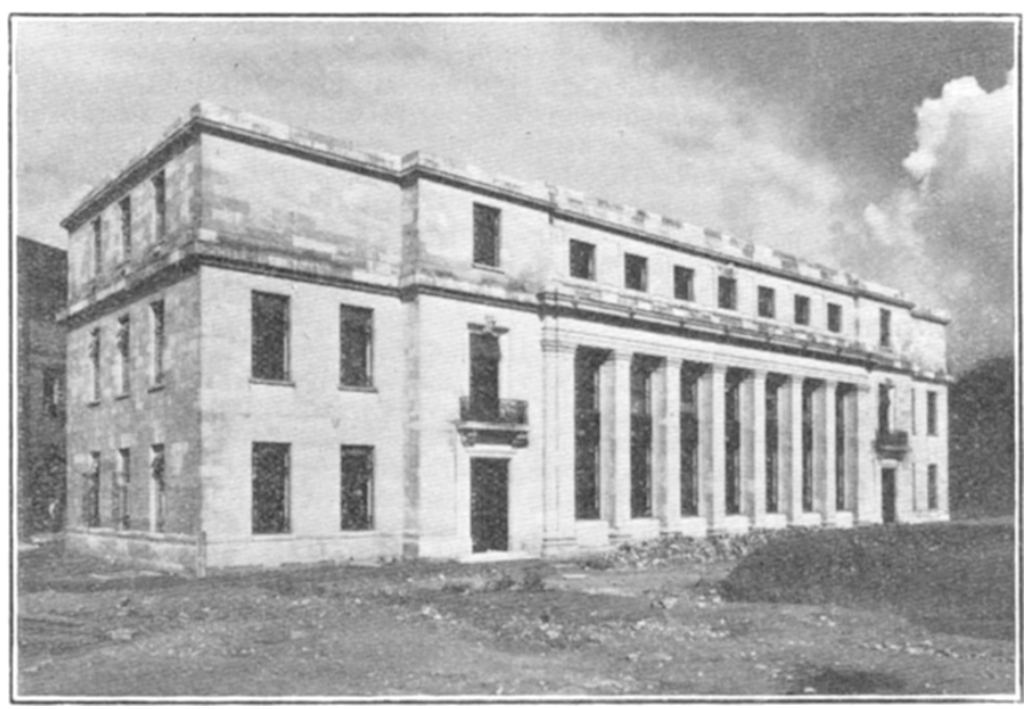

FIG. 1.-Mining Department, University of Leeds. independent means of access to this floor, two being at the front and two at the rear of the building. The main laboratory largely occupies the ground floor and is entirely given up to work on the preparation of coal and ores for the market. Working models of the principal appliances used in coal-cleaning and ore-dressing operations are installed. Adjacent to, but entirely separate from, the main laboratory is the crushing laboratory. Here an ore is treated, progressively if need be, by jaw crushers, rolls, stamps, and ball mills. The sampling room is completely isolated from the remainder of the building so as to reduce the risk of contamination during the grinding and subsequent treatment of coal or ore samples.

The principal units housed in the machinery room are: (1) a 25 h.p. vertical 2-stage air-compressor complete with all accessories required for testing purposes ; (2) 32 h.p. motor-generator set with autotransformer starter and six Reyrolles distribution panels ; (3) fullsize air - driven turbine chain coal - cutter kindly presented by Messrs. Anderson Boyes and Co. ; and (4) two air - driven jigging-conveyor engines with lengths of troughs and accessories kindly presented by the British Jeffrey. Diamond Company.

In the basement, two 20-in. diameter Sirocco fans are installed together with about a hundred feet of fan gallery for experimental ventilation siderable importance to the successful teaching of mining practice.

The first or middle floor is apportioned into laboratories for wet and dry assaying, a gas-analysis laboratory, a dark room for photometric and safetylamp work, a balance room, two research laboratories, and the departmental offices. The balance room is conveniently situated between the assaying and the research laboratories. One of the latter, and the research laboratory on the top floor, are to be occupied by a section of the Fuel Research Board for the physical and chemical survey of the West Yorkshire Coalfield. The other, and larger, research laboratory is fitted with all services necessary for the investigation of any physical or chemical problem associated with modern mining practice. It has so far been used by that branch of the Safety in Mines Research Board dealing with improvements in self-contained breathing appliances for use in mines. Entrance to any one of the laboratories on the first floor can be made only from the main corridor, a feature especially desirable in research work.

The ground floor comprises the main laboratory, crushing laboratory, sampling room, machinery room, ore bins, workshop, and stores. There are four work. The fans are so arranged that they can be operated either singly, in series combination, or in parallel combination. A series of compressed-air pipe lines of various diameters is fitted along one of the walls of the basement, the arrangement incorporating different forms of metering devices, the whole being laid out for experimental work in compressed-air power service.

A special feature of the building is the ready accessibility of all services. In all there are twelve services, namely, a.c. two-phase, a.c. single-phase, d.c. power, electric lighting, water at mains pressure, water at constant head low pressure from the large capacity tank on the roof, domestic hot water, waste water, gas, compressed air, heating, and steam. Each service conduit system is painted a different colour, and the diagram giving the key to this colour scheme hangs in the main laboratory. In the laboratories the main services required are carried openly, along the top of, but are quite independent of, the benches. Tappings are arranged at intervals commensurate with the particular requirements. The cupboards below benches are all small standardsized units and are readily removable or interchangeable. The general arrangement of the services is 
thus one which facilitates their efficient maintenance and permits of ready extension whenever necessary.

All the electrical apparatus is earthed and adequately protected. Transformers for the supply of two-phase and single-phase a.c. are situated outside the main building, the distribution panels only being housed in the crushing laboratory. Reyrolle B.E.S.A. plugs (15 amp. and 5 amp.) are fitted throughout the laboratories for a.c. power and Reyrolle standard are used for d.c. The building is heated chiefly by the modern panel system, the panels being fitted on the walls or ceilings. Coke-fired boilers, separately housed in the basement, provide the hot water for heating and other purposes both in the Mining and the Fuel Departments.

\section{Conference on Soil Science Problems.}

THE Imperial Bureau of Soil Science, formed in 1 May 1929 to assist workers on soil science throughout the Empire by providing technical information and promoting personal contacts between them, held its first Conference on Soil Science Problems on Sept. 16-18, at Rothamsted Experimental Station, Harpenden, with which it is in close association. The first day was made the occasion of the annual visit of Empire agricultural officers to the Station. The visitors, who included representatives from Australia, Canada, Ceylon, Gold Coast, India, New Zealand, Nigeria, Sierra Leone, South Africa, Straits Settlements, Federated Malay States, Sudan, Trinidad, Uganda, and Great Britain, were entertained to lunch, following a tour of the farm in which the classical and modern experiment plots were demonstrated. During the luncheon, the Conference was formally opened by the Right Hon. W. G. A. OrmsbyGore; and later, an inspection of the laboratories was made and the work of the various departments demonstrated in groups, according to the individual interests of the specialist workers present.

The work of the Conference began on the following day, Sir A. D. Hall presiding, and a discussion on the mechanical analysis of soils was opened by Prof. G. W. Robinson (Bangor), who gave an account of the results of his work in comparing methods proposed by the International Society of Soil Science. He showed that similar figures were obtained by different methods with the majority of the soils examined. The main points of the discussion that followed were: The application of the proposed methods to tropical soils and the advisability of choosing a method suited to each particular class of soil ; modifications in tech nique affecting the degree of dispersion of the soil by the omission, with some soils, of acid and peroxide treatment; and the proposed use of sodium hypobromite or chlorine peroxide for the oxidation of organic matter prior to analysis.

Mr. A. W. R. Joachim (Ceylon), who opened the discussion on available phosphorus and potash, spoke with particular reference to the reliability of laboratory tests for availability, such as the Dyer citric acid test and the physiological methods of Mitscherlich and Neubauer, suggesting that more use might be made of data for exchangeable potassium as an index of potash availability. During the discussion, reference was made to the desirability of eliminating errors due to seasonal effects and faulty sampling of the soil, and to the need of trustworthy, rapid, chemical methods to replace the tedious physiological tests. The suggestion was also made that the undoubted popularity of the latter methods on the Continent, and particularly in Germany, could be partly attributed, first, to a lower state of soil fertility than is prevalent in Great Britain; secondly, to unbalanced fertiliser additions, in the past, to soils in the same area, due in some cases to War shortage of one or other of the fertiliser components; thirdly, to legal difficulties involved in the sale of mixed fertilisers; and lastly, to conditions of land tenure.

A discussion on soil reaction and lime requirement was then opened by Mr. P. E. Turner (Trinidad) with an account of his work on the correlation of $p H$ measurements of the soil with its degree of saturation with lime. This led to a discussion, principally on the correlation of $p \mathrm{H}$ values with other factors and the significance of soil reaction, especially in relation to the tolerance of specific plants.

At the afternoon meeting, the chairman, Dr. A. C. D. Rivett (Australia), opened a discussion on the work of the Imperial Bureau of Soil Science. Sir David Chadwick, secretary of the Executive Council of the Imperial Agricultural Bureaux, referring to the need of unity among research workers of the Empire which presaged the inauguration of the Bureau at the Imperial Agricultural Research Conference of 1927 , said that the financing of the Bureau from a common fund derived from contributing governments marked a new departure in the constitution of the Empire. The work of the Soil Bureau for the year was then outlined by the Director, Sir John Russell. In the general discussion that followed, recommendations were made, many by overseas representatives, with the view of increasing further the usefulness and efficiency of the Bureau's activities. Finally, a proposal that the Bureau should hold annually a one-day informal conference was adopted.

The morning of Sept. 18, devoted to a discussion of soil survey, with Sir Thomas Middleton as chairman, began with an address on the soil resources of the Empire, by Sir John Russell, in which he said that no basis sufficiently broad to allow the comparative study of regions so widely scattered as those of the Empire has existed until recent years. The grouping of soils is determined, first, by climatic factors, and secondly, by geological factors. Topographical features also play an important part; but as first approximate generalisation, similar climatic conditions may be said to produce similar soil types and a tendency to form similar agricultural conditions. This is well seen in comparing the great regions of the British Empire and should serve as a basis for a valuable survey of the soil's resources. In concluding, he said that there is among manufacturers of the Empire a general working towards mutual agreements to reduce unnecessary competition and over-production; the agricultural scientific workers of the Empire are now organised through the Agricultural Bureaux to pool their information and ensure the maximum result for their efforts : it remains to bring about an organised agriculture for the Empire, based on sound soil and agricultural surveys, to ensure the best use of Imperial resources. A discussion on the position of soil survey in the Empire was then opened by Dr. F. J. Martin (Sierra Leone) with a description of a survey undertaken by him which resulted in an extension of rice-growing areas in Sierra Leone. Examples of similar extensions were brought forward during the general discussion. Sugar cane crops have been considerably extended in India through irrigation, by carrying out survey work which distinguishes between areas that would or would not respond to irrigation. The need for further work of that kind, especially in north - west India, and for: 